DE9 1006815

\title{
KINETIC MEASUREMENTS ON ELEMENTARY FOSSIL FUEE COMBUSTION REACTIONS OVER WIDE TEMPERATURE RANGES
}

\author{
Progress Report \\ For the Period December 1, 1989 - November 30, 1990
}

\author{
Arthur Fontijn \\ High-Temperature Reaction Kinetics Laboratory \\ The Isermann Department of Chemical Engineering \\ Rensselaer Polytechnic Institute \\ Troy, New York 12180 3590
}

January 1991

Prepared for

THE U.S. DEPARTMENT OF ENERGY

AGREEMENT NO. DE-FG02-84ER 13224

\section{DISCLAIMER}

This report was prepared as an account of work sponsored by an agency of the United States Government. Neither the United States Government nor any agency thereof, nor any of their employees, makes any warranty, express or implied, or assumes any legal liability or responsibility for the accuracy, completeness, or usefulness of any information, apparatus, product, or process disclosed, or represents that its use would not infringe privately owned rights. Reference herein to any specific commercial product, process, or service by trade name, trademark, manufacturer, or otherwise does not necessarily constitute or imply its endorsement, recommendation, of favoring by the United States Government or any agency thereof. The views and opinions of authors expressed herein do not nexessarily state or reflect those of the Unired States Government or any agency thereof. 


\section{INTRODUCTION AND METHOD}

The goals of this work are to provide accurate data on the temperature dependence of the kinetics of elementary combustion reactions (i) for use by combustion modelers, and (ii) to gain a better fundamental understanding of, and hence predictive ability for, the chemistry involved. Experimental measurements are made using the pseudo-static HTP (high-temperature photochemistry) technique. This approach allows observations on single reactions in the 300 to $1800 \mathrm{~K}$ temperature range to be made. Typical total (bath gas) pressures are in the 100 to 1000 mbar range. Ground-state $\mathrm{O}$ atoms are produced by flash phetolysis of $\mathrm{O}_{2}$ or $\mathrm{CO}_{2}$ or ArF excimer laser-photolysis of $\mathrm{SO}_{2}$. The relative atom concentrations are monitored by resonance fluorescence purnped by a $\mathrm{cw}$ microwave discharge flow lamp. The molecular reactantin-excess is introduced through a cooled inlet. Adequate time for mixing, 0.1 to $10 \mathrm{~s}$, between this inlet and the photolysis/observation zone is achieved by using slow flo:/s (typically less than $20 \mathrm{~cm} \mathrm{~s}^{-1}$ ).

\section{PROGRESS}

In the reporting period our work on the $\mathrm{O}+\mathrm{HCl}$ reaction was published, 1 experimental work on the $\mathrm{O}+$ benzene and $\mathrm{O}+1$-butene reactions was completed, and measurements on the $\mathrm{O}+$ isobutene reaction were initiated.

\section{The O-Atom Benzene Reaction}

Fig. 1 summarizes the present measurements and compares them to those of earlier workers $2-4$ and Wagner's shock tube study, 5 which appeared while our work was in progress. All the measurements are in excellent agreement. The present work, which has covered the $600-1310 \mathrm{~K}$ regime, has bridged the gap between the lower temperature work $(\mathrm{T}<870 \mathrm{~K}$ ) and the 1200 to $1450 \mathrm{~K}$ shock tube study. While Wagner and coworkers flow tube work below $680 \mathrm{~K}$ had a hint of curvature (which they thought might be an experimental artifact), their shock tube and the combined 
work shows no such trend. A simple Arrhenius expression $\mathrm{k}(\mathrm{T})=3.9 \times 10^{-11}$ $\exp (-2364 \mathrm{~K} / \mathrm{T}) \mathrm{cm}^{3}$ molecule-1 $\mathrm{s}^{-1}$ best represents all the data from 300 to $1450 \mathrm{~K}$. At low temperatures the reaction is known to proceed by $\mathrm{O}$-atom addition to the aromatic ring. 2,3 While an abstraction reaction is likely to be of importance above some temperature, Fig. 1 clearly indicates that such is not yet the case in the $1400 \mathrm{~K}$ range. This is in agreement with the $61.5 \mathrm{~kJ} / \mathrm{mol}$ activation energy estimated from BEBO calculations. 3

A publication based on these results is in preparation.

\section{The O-Atom 1-Butene Reaction}

We have made measurements on this reaction from 340 to $1110 \mathrm{~K}$. The data are best represented by the expression $\mathrm{k}(\mathrm{T})=2.3 \times 10^{-17}(\mathrm{~T} / \mathrm{K})^{1.95} \exp (330 \mathrm{~K} / \mathrm{T})$ $\mathrm{cm}^{3}$ molecule-1 $\mathrm{s}^{-1}$. As may be seen from Fig. 2, this result is in good agreement with previously reported low temperature $(\mathrm{T}<500 \mathrm{~K}$ ) data, 6-9 as well as with the best fit expression for the $260-860 \mathrm{~K}$ range given in an abstract by Perry. ${ }^{10}$ It has been postulated that the reaction proceeds by addition at low temperatures, while hydrogen-atom abstraction will become increasingly important at elevated temperatures.6.7 Apparent confirmation for abstraction comes from the detection of $\mathrm{OH}$ in molecular beam experiments with $\mathrm{LIF}^{11}$ and mass spectrometer 12 detection.

To establish to what extent the abstraction channel could be the cause of the sharp upward curvature in the Arrhenius plot, Fig. 2, we have performed a Transition State Theory (TST) calculation for it and added the resulting rate data to those for the addition channel from the TST calculation by Singleton and Cvetanovic. 7 Their calculation involved fitting to experimental $k(T)$ data. For the abstraction channel we used the $8.0 \mathrm{~kJ} \mathrm{~mol}^{-1}$ energy barrier from one of the beam studies, 11 combined with the usual partition functions. The resulting sum of the rate coefficients is shown in Fig. 2 as "Theory" and can be seen to give pronounced curvature, but to fall increasingly below the experimental curve with increasing $T$. Further calculations are in progress, which will be included in the manuscript in preparation. 


\section{The O-Atom Isobutene Reaction}

Fig. 3 gives the Arrhenius plots for the O-atom reactions of all four butenes taken from the expressions in Perry's abstract. ${ }^{10}$ His 1-butene expression is as noted above, in excellent agreement with ours. However, our first observations in the 350$1050 \mathrm{~K}$ range are in qualitative agreement only with his measurements, and suggest a much flatter plot. If confirmed, this also casts some doubt on his cis- and trans-2butene observations.

\section{REFERENCES}

1. K. Mahmud, J-S. Kim and A. Fontijn, "An HTP Kinetics Study of the $\mathrm{O}+\mathrm{HCl}$ Reaction from 350-1480 K, J. Phys. Chem., 94, 2994 (1990).

2. J.M. Nicovich, C.A. Gump and A.R. Ravishankara, "Rates of Reactions of O( $\left.{ }^{3} \mathrm{P}\right)$ with Benzene and Toluene", J. Phys. Chem., 86, 1684 (1982).

3. M. Tappe, V. Schliephake and H.Gg. Wagner, "Reactions of Benzene, Toluene and Ethylbenzene with Atomic Oxygen $\left(\mathrm{O}^{3} \mathrm{P}\right)$ in the Gas Phase, Z. Physik. Chem. N.F., 162, 129 (1989).

4. A.J. Colussi, D.L. Singleton, R.S. Irwin and R.J. Cvetanovic, "Absolute Rates of Oxygen (3P) Atom Reactions with Benzene and Toluene", J. Phys. Chem., 79, 1900 (1975).

5. H.l. Leidreiter and H.Gg. Wagner, "An Investigation of the Reaction Between $\mathrm{O}\left({ }^{3 P}\right)$ and Benzene at High Temperatures", Z. Physik. Chem. N.F., 165, 1 (1989).

6. R.E. Huie, J.T. Herron and D.D. Davis, "Absolute Rate Constants for the Addition and Abstraction Reactions of Atomic Oxygen with 1-Butene over the Temperature Range 190-491 K", J. Phys. Chem., 76, 3311 (1972).

7. D.L. Singleton and R.J. Cvetanovic, "Temperature Dependence of the Reactions of Oxygen Atoms with Olefins", J. Am. Chem. Soc., 28, 6812 (1976).

8. R. Atkinson and J.N. Pitts, Jr., "Absolute Rate Constants for the Reaction of $\mathrm{O}\left({ }^{3} \mathrm{P}\right)$ Atoms with a Series of Olefins over the Temperature Range 298-439 K", J. Chem. Phys., 67, 38 (1977).

9. R. Browarzik and F. Stuhl, "Temperature Dependence of the Rate Constants for the Reactions of Oxygen Atoms with Ethene, Propene, and 1-Butene", J. Phys. Chem., 88, 6004 (1984). 
10. R.A. Perry, "Kinetics of the Reaction of O Atoms with Olefins over the Temperature Range 260-860 K using Laser Photolysis-Chemiluminescence", Abstracts of Papers for the 188th American Chemical Society National Meeting, Philadelphia, Pennsylvania, August 1984.

11. K. Kleinermanns and A.C. Luntz, "The Chemical Dynamics of Hydrogen Atom Abstraction from Unsaturated Hydrocarbons by $\mathrm{O}\left({ }^{3} \mathrm{P}\right) ", J$. Chem. Phys., 77, 3533 (1982).

12. B. Blumenberg, K. Hoyermann and R. Sievert, "Primary Products in the Reactions of Oxygen with Simple and Substituted Hydrocarbons", Sixteenth Symposium (International) on Combustion, p. 841, The Combustion Institute, 1977. 


\section{$\mathrm{T}, \mathrm{K}$}

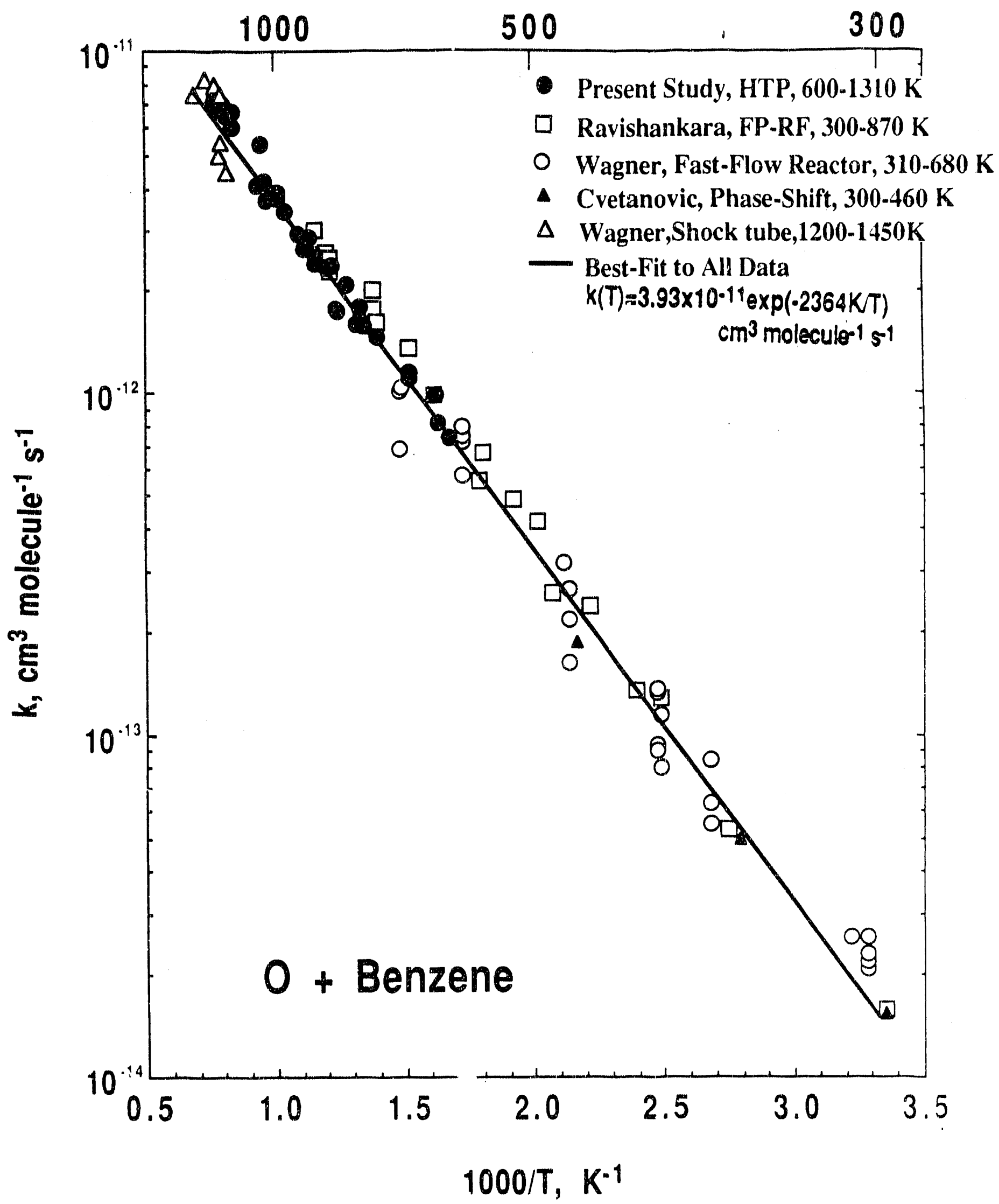

Figure 1. Summary of Rate Coefficients of the $\mathrm{O}+\mathrm{C}_{6} \mathrm{H}_{6}$ Reaction. 


\section{$\mathrm{T}, \mathrm{K}$}

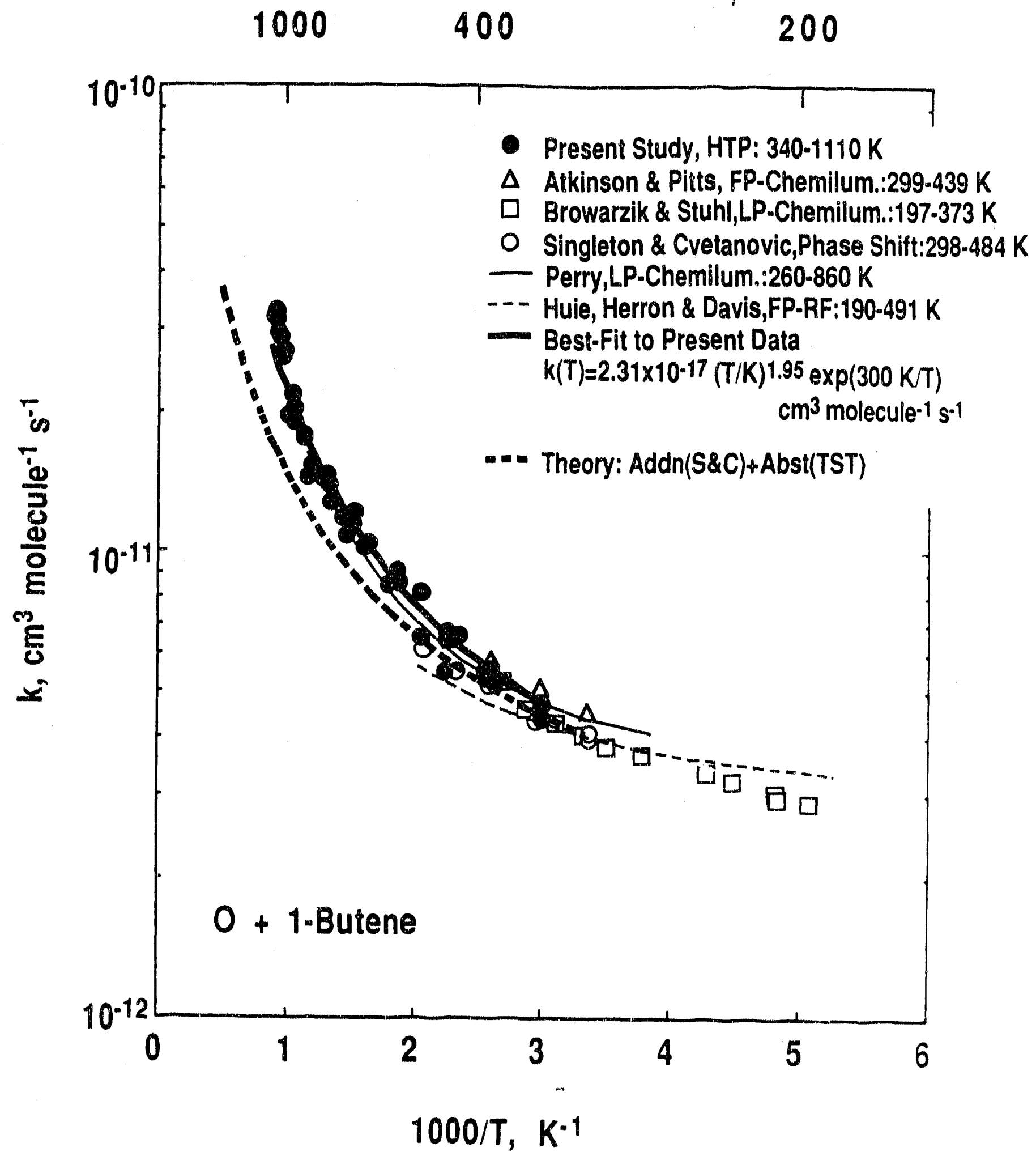

Figure 2. Summary of Rate Coefficients of the $\mathrm{O}+1$-Butene Reaction. 


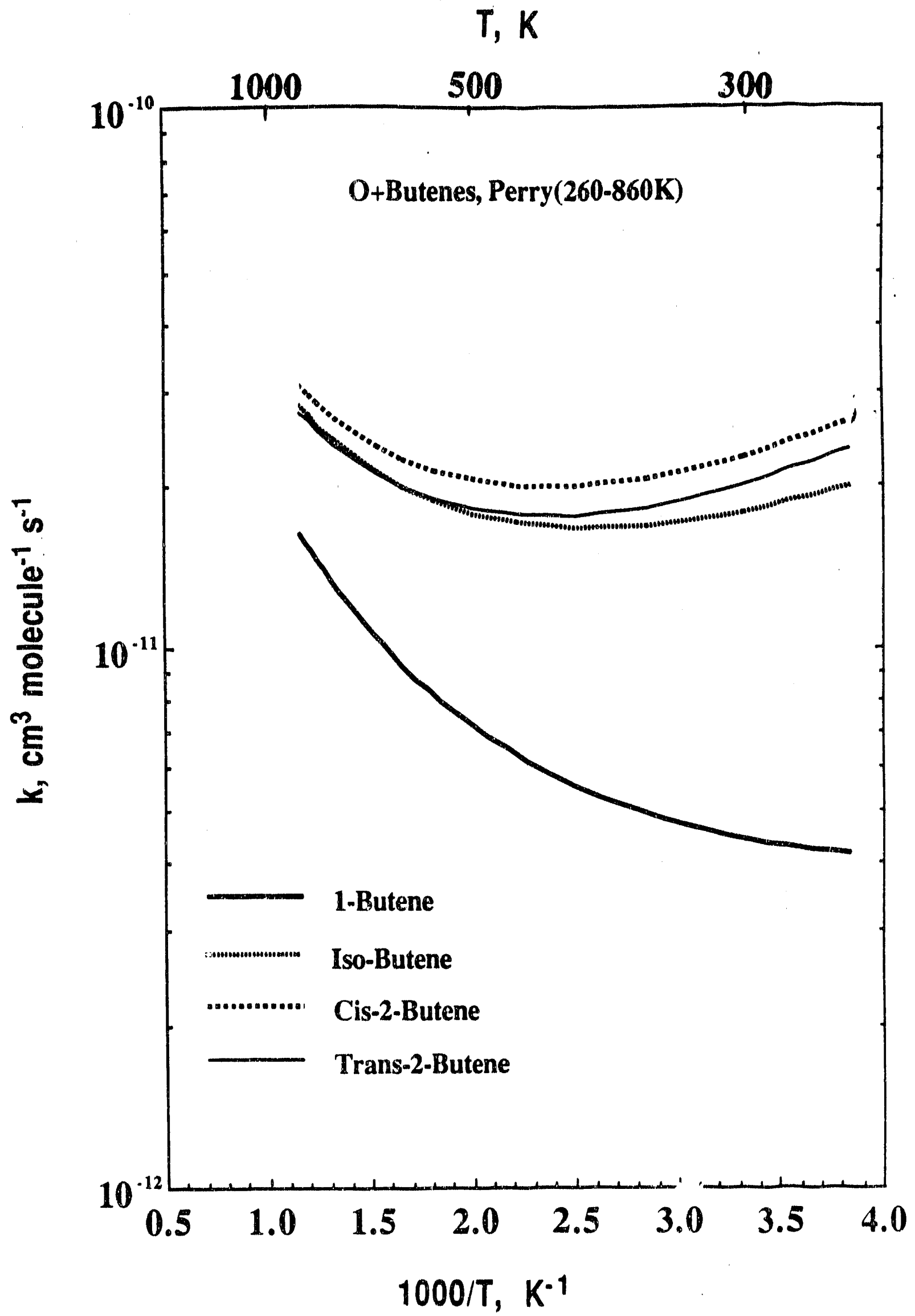

Figure 3. Comparison of the Arrhenius Plots of the O-Atom Reactions With the Four Butenes, as given by Perry.10 

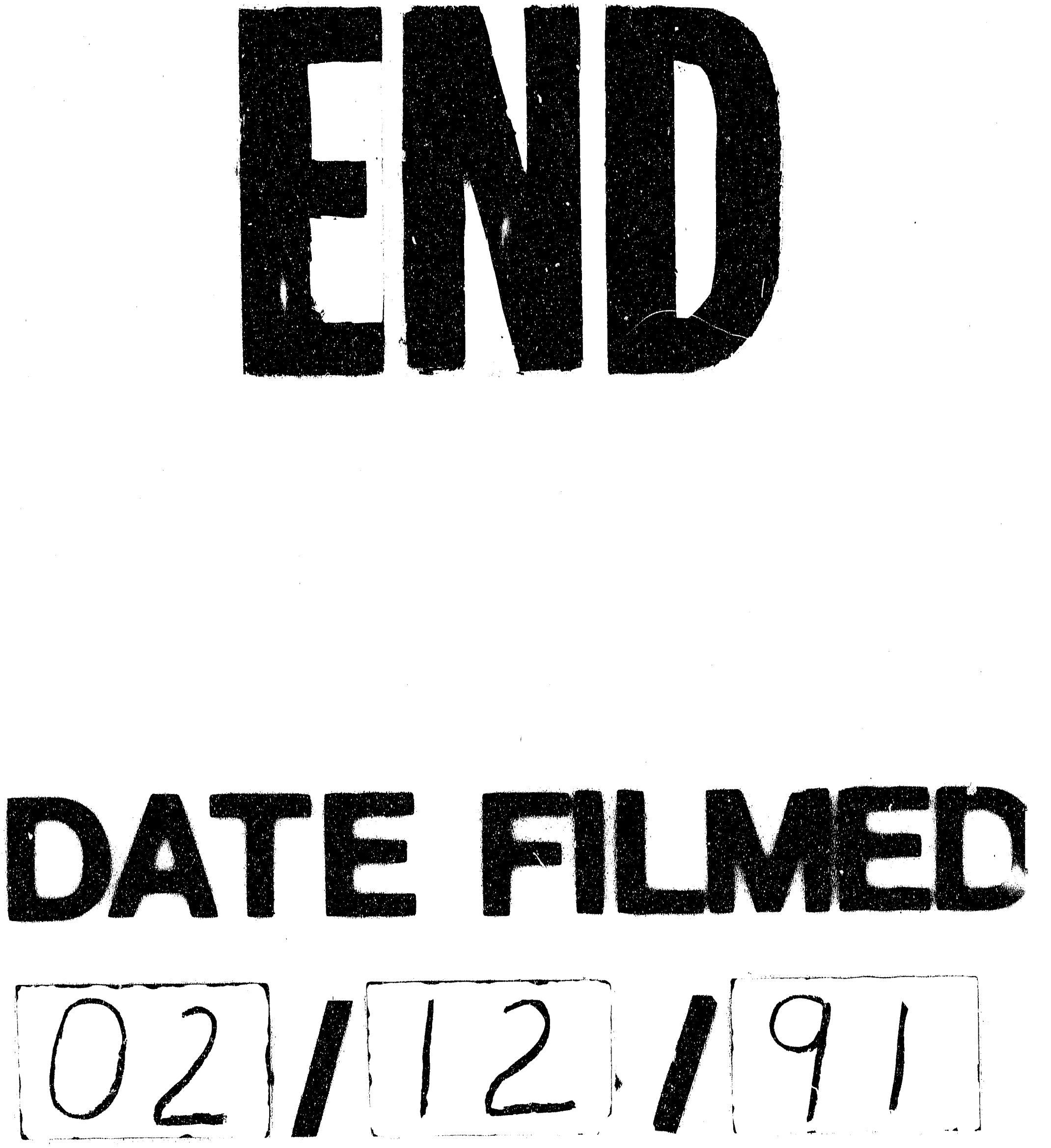
; 